\title{
Macrocytosis in multiple sclerosis. A study in 82 de novo Arab patients
}

\author{
A S Najim Al-Din, M Khojali, H Habbosh, S Farah, A R Idris, F Al-Muhtasib
}

\begin{abstract}
Macrocytosis, without anaemia, was common in 82 de novo multiple sclerosis patients compared with a similar number of age and sex matched controls. This was an early phenomenon in the course of the disease and was not influenced by the age of the patients nor the duration of the disease. None of the patients proved to have pernicious anaemia, yet the similarity in the geographical and sex distribution as well as the similarity in HLA associations of multiple sclerosis and pernicious anaemia may indicate that both diseases are under similar genetic influence.
\end{abstract}

Mild macrocytosis has been reported in cases of multiple sclerosis (MS) without anaemia. ${ }^{12}$ This has raised the question of whether an abnormality of vitamin $\mathrm{B}_{12}$ absorption, transport or metabolism was associated with MS. More recently MS patients with unusual vitamin $B_{12}$ deficiencies were described. ${ }^{3-5}$ To verify this observation we retrospectively studied the haemoglobin $(\mathrm{Hb})$ and the red cell mean corpuscular volume (MCV) in our group of Arab MS patients.

\section{Patients and methods}

The study population comprised 82 clinically definite MS Arab patients who fulfilled the Poser et al criteria. ${ }^{6}$ All of them presented within four years of the onset of the first symptom and were not diagnosed before or had received specific medications before presentation to us. Their $\mathrm{Hb}$ and $\mathrm{MCV}$ values were recorded before the initiation of any form of specific therapy. Each MS patient was matched for sex and age with a neurological patient who attended a neurology outpatient clinic during the same period (1985-89). Groups of patients who had conditions which led to abnormal $\mathrm{Hb}$ and/or MCV (epileptics on anticonvulsants, dementia, depression, neuropathies and subacute combined degeneration of the cord) were excluded. Among the 82 controls 32 had tension headache, 27 migraine, 15 spondylotic lumbar or cervical spinal diseases, six benign intracranial hypertension and two had peripheral vestibular disease. None of the MS patients nor the controls were on drugs that were likely to alter either measurement. All blood counts were measured using Coulter Blood Counter Model .S-Plus (Coulter Electronics, Luton,
UK). All data were entered into the vax-11/ 8810 computer and analysis was carried using SPSS package.

\section{Results}

The age, sex distribution and haematological data of patients and controls are shown in table 1 . Fifty one $(62 \%)$ of the patients had a duration of disease of one to 12 months before haematological evaluation and only five $(6 \%)$ had a duration of three to four years before these tests were performed. The mean duration of disease was 15.9 months (range 1-48 months) among all cases. The two groups were similar in age, sex distribution and mean haemoglobin levels. In both groups the mean (SD) MCV was found to be within normal limits, the normal reference range for $\mathrm{MCV}$ in our laboratory is 84 (7) $\mathrm{fl}$. The MS patients exhibited an elevated MCV $[87.5(6.4) \mathrm{fl}]$ when compared with controls [84.1 (5.6) fi] and the difference was found to be highly significant $(p<0.0001)$. This difference was also observed when comparing MS female and male patients with their respective sexes among the controls and it was found to be highly significant, $p<0.009, p<0.003$, respectively (table 2). There was no influence of age on the level of MCV among both patients and controls. Likewise the duration of the disease before haematological tests were performed had no influence on the MCV.

Only four females from both groups had an MCV lower than the normal limits for our laboratory $(77 \mathrm{fl})$. Four $(5 \%)$ of the controls had an MCV higher than the upper limits for normal $(91 \mathrm{fl})$, this ranged from $91 \cdot 6-95 \cdot 7 \mathrm{fl}$. Abnormally high MCV was observed in 22 $(27 \%)$ of the patients with a range of 91.6 $100 \mathrm{fl}$. Sixty three $(77 \%)$ of the patients compared with $40(49 \%)$ of the controls had an MCV higher than the normal mean. Even when the 22 patients with abnormally high MCV and the four with the abnormally low MCV were excluded, still $73 \%$ of the remaining $56 \mathrm{MS}$ patients with normal MCV had a measurement which was higher than the normal mean.

Only two MS patients, one with an MCV of 94.8 and the other $100 \mathrm{fl}$ had a low haemoglobin $(10.8$ and $10.9 \mathrm{gm} / \mathrm{dl}$ respectively). In neither was the $B_{12}$ metabolism studied on first presentation.

The serum $B_{12}$ and folate were assayed in 14 of the patients reported above, who were not on azothioprine, in 1989 and all the values were within normal limits. 
Table 1 Sex, mean (SD) age, haemoglobin and $M C V$ among $\left(B^{2}\right)$ multiple sclerosis and controls and neurological control

\begin{tabular}{|c|c|c|c|}
\hline & $M S(n=82)$ & Control $(n=82)$ & $p$ \\
\hline Mean (SD) age (years) & $31 \cdot 7(8 \cdot 7)$ & \multirow{5}{*}{$\begin{array}{l}31 \cdot 7(8 \cdot 7) \\
30: 52 \\
13 \cdot 5(1 \cdot 5) \\
84 \cdot 1(5 \cdot 6)\end{array}$} & NS \\
\hline Sex ratio $M: \vec{F}$ & $30: 52$ & & \multirow{4}{*}{$\begin{array}{l}\text { NS } \\
p<0.0001 \\
t=3.62\end{array}$} \\
\hline Mean (SD) haemoglobin gm/dl & $13 \cdot 8(1.6)$ & & \\
\hline${ }^{\star}$ Mean (SD) MCV & $87 \cdot 5(6 \cdot 4)$ & & \\
\hline Mean (SD) duration months & $15.9(13.6)$ & & \\
\hline
\end{tabular}

$\star$ Normal laboratory value $=84(7 \cdot 0) \mathrm{fl}$.

Table 2 Mean (SD) age, haemoglobin and MCV by sex among MS patients and controls

\begin{tabular}{|c|c|c|c|c|}
\hline & \multicolumn{2}{|l|}{ Females } & \multicolumn{2}{|l|}{ Males } \\
\hline & $\begin{array}{l}M S \\
n=52\end{array}$ & $\begin{array}{l}\text { Control } \\
n=52\end{array}$ & $\begin{array}{l}M S \\
n=30\end{array}$ & $\begin{array}{l}\text { Control } \\
n=30\end{array}$ \\
\hline $\begin{array}{l}\text { Mean (SD) age (years) } \\
\text { Mean (SD) haemoglobin g/dl } \\
\text { Mean (SD) MCV fl } \\
\text { Mean (SD) duration month }\end{array}$ & $\begin{array}{l}30.1(8.5) \\
13.0(1 \cdot 2) \\
86.0(6 \cdot 8)^{\star} \\
14.4(13.0) \ddagger\end{array}$ & $\begin{array}{l}30 \cdot 1(8 \cdot 5) \\
12 \cdot 8(1 \cdot 3) \\
82 \cdot 7(5 \cdot 7) \\
-\end{array}$ & $\begin{array}{l}34 \cdot 5(8 \cdot 5) \\
15 \cdot 0(1 \cdot 5) \\
90 \cdot 1(4 \cdot 6) \dagger \\
18 \cdot 5(14 \cdot 4)\end{array}$ & $\begin{array}{l}34.5(8.5) \\
14.7(1 \cdot 1) \\
86.4(4.3)\end{array}$ \\
\hline
\end{tabular}

* Significant difference $\mathrm{p}<0.009 \mathrm{t}=2.67$

+ Significant difference $p<0.003 t=3.07$.

$\ddagger$ Difference not significant when comparing females and males.

\section{Discussion}

The observation by Reynolds of unusual vitamin $B_{12}$ deficiencies in 10 patients might have implications on the pathoaetiology of MS. $^{3-5}$ The report by his group of macrocytosis without anaemia in $27 \mathrm{MS}$ patients gives further support for this observation. ${ }^{2}$

We studied this phenomenon in 82 de novo patients with relatively short duration of the disease to overcome any effect of drug or dietary influences. Our data supports the study by Reynolds ${ }^{34}$ that a tendency for macrocytosis without anaemia is noted in MS. The majority of our MS patients were thus found to have an MCV value higher than the normal mean early in the course of their disease before the start of any specific therapies. More significant is the observation that $27 \%$ of our patients had abnormally high MCV. Yet anaemia was exceptional as it was noted in only two patients with a high MCV. The macrocytosis was not a function of the duration of the disease and was frequently discovered in patients who were studied within a week of presentation with the first symptom. Although we studied the serum $B_{12}$ and folate in a limited number of patients (several years after the onset) these were normal.

The significance of our observation and previous reports is subject to debate. Although none of our patients proved to have pernicious anaemia (PA) it is interesting that both MS and PA are most common in whites of northern European ancestry and both affect females more than males. ${ }^{5}$ Both diseases are of unknown aetiology where both genetic susceptibility and autoimmune reaction are postulated. Furthermore, PA is reported to have a geographical distribution similar to $M S .^{5}$ Interestingly the HLA studies in PA have shown an association with HLA-A $3,{ }^{7}$ HLAB7 ${ }^{8}$ HLA-DRW $2^{9}$ and DR2 $2^{10}$ similar to MS.

Whether metabolic abnormalities of vitamin $B_{12}$ play a role in the aetiology of MS is not yet clear. The phenomenon observed probably reflects a genetic overlap of two different diseases. It is possible that both of these diseases require a common genetic susceptibility but are manifest under the influence of different enviromental factors.

1 Plum CM, Fog T. Studies in multiple sclerosis. Acta Neurol Scand 1959;34(Suppl 128):13-18.

2 Crellin RF, Bottiglier T, Reynolds EH. Multiple sclerosis and macrocytosis. Lancet 1989;i:1157.

3 Reynolds EH, Linnell JC. Vitamin B12 deficiency, demyelination and multiple sclerosis. Lancet 1987;ii:920.

4 Reynolds EH, Linnell JC. Multiple sclerosis and vitamin B12 metabolism-a new clue. J Neurol Neurosurg Psychiatry 1988;51:739.

5 Chanarin I. The megaloblastic anaemias. Oxford: Blackwell, 1979.

6 Poser CM, Paty DW, Scheinberg L et al. New diagnostic criteria for multiple sclerosis: guidelines of research protocols. Ann Neurol 1983;13:227-31.

7 Chanarin I, Knight S, O'Brien J, James D. HL-A groups in pernicious anaemia. Br J Haematol 1976;33:539-41.

8 Goldstone AH, Voak D, Cawley JC, Irvine WJ. HLA antigens in pernicious anaemia. Clin Exp Immunol antigens in pern

9 Thomsen $M$, Jorgensen $F$, Brandsborg $M$, et al. Association of pernicious anaemia and intrinsic factor antibody with

10 Ungar B, Mathews JD, Tait BD, Cowling DC. HLA-DR patterns in pernicious anaemia. $B M J 1981 ; 1: 798-800$

11 Van Den Berg-Loonen EM, Hilterman TCM, Bins M Nijenhuis LE, Engelfriet CEP. Increased incidence of HLA-DR2 in patients with pernicious anaemia. Tissue Antigens 1982;19:158-60. 